it would be tough reading for a newcomer to the subject. The choice of approach is, of course, Jacobs's prerogative. Even so, I would like to have seen a somewhat longer introductory chapter discussing in greater detail the philosophy and nomenclature of the subject. Jacobs is, however, to be congratulated on sticking to egs units throughout. It really is quite monstrous that attempts should be made to force all scientific disciplines into using a system of units which may be appropriate to some but not others. The tragedy is that, irrespective of whether or not geophysicists ultimately capitulate, modern students brought up on a strict diet of SI units will be largely cut off from geophysics' most glorious decades.

Peter J. SMith

\section{INTRODUCTION TO PHYSICS}

\section{General Physics}

By G. J. Aitchison. Pp. viii + 522. (Chapman and Hall: London, April 1970.) $60 \mathrm{~s}$.

THIs book is described in the preface as intended for students doing first year university physics courses with the probability of terminating their study of the subject at that level. Before commenting on this particular use, let it first be said that this is an extremely satisfactory book about physies, with a freshness of thought and an appeal to down-to-earth and commonsense reason which makes it something that few textbooks of physics arereadable. It is therefore a little disappointing that it moves forward to what has for a decade or two been the inevitable culmination of any treatment of "general physics"--.high energy nuclear physics and the strange particles. Although this section is well done, one hopes that before long the much more open-ended climax offered by cosmology will replace this restricted field in the canon.

One is tempted to speculate whether this book would not be an admirable introduction to the subject for a very large number of able people who would like to understand something about physics, but have never followed it beyond school days, at least as part of their formal education. It has the qualities of a book which can be read and thought about at the pace which suits the reader, and with a little determination to follow the author's advice and do all the examples, the exercise could hardly fail to be profitable.

As a first year textbook, it has the same excellent qualities, but for this purpose it would be necessary to shape the courses to be compatible with the aims and methods of the book. A general impression is that rather more time would be needed than is sometimes allocated to a "subsidiary" subject; moreover, any examination on the course would have equally to be related to the author's view.

Here is a book which makes physics neither romote nor mysterious, and it deserves to do well.

\section{J. G. WILSON}

\section{CONDUCTING STATES}

\section{Amorphous and Liquid Semiconductors}

Edited by Sir Nevill Mott. (Proceedings of the International Conference held at the Cavendish Laboratory, Cambridge, September 24-27, 1969.) Pp. xii +626. (NorthHolland: Amsterdam, 1970.) Hfl. 108; 252s; $\$ 30$.

THE editor and everybody concerned must be congratulated for producing this very valuable volume in record time, though a penalty is paid in many printing errors. Interest in amorphous and liquid semiconductors has grown rapidly in the past few years, but our knowledge of them is still in its infancy, so that many of the contributions are in the nature of pioneer work.

Even if some of these substances have important technological applications, the theory is of predominant interest at this stage. It is much more complicated than for crystalline semiconductors and its principal aim is to discover the differences between regular and disordered structures in the electronic energy spectrum and in the character of the energy states, the problem of the localization of these states being in the forefront. The very clear review paper on the theory is by Morrel Cohen, who points out what may be universal features of the electronic structures of disordered systems. He discusses the model which has emerged largely through the work of Sir Nevill Mott. An isolated energy band in a disordered material is assumed to consist of extended states between two critical energies, with tails of localized states outside these energies. Tails from neighbouring bands may overlap. The transport mechanism also changes at the critical energies $E_{c}$; for the extended states it is similar to that in crystals, but, because the carriers are almost continuously under the influence of the scattering centres, their motion is more like a Brownian motion than a wave propagation; for the localized states we have phonon assisted hopping. The mobility changes by several orders of magnitude within a range of order $k T$ about $E_{\mathrm{c}}$, thus it is more appropriate to speak of a mobility edge and mobility gap rather than of an energy gap.

S. F. Edwards explores, in an elegant paper, the analogy of the Mott transition with a phase change of a thermodynamical system. He establishes a relation between the density of states of the electrons in a disordered system and the thermodynamics of a flexible chain, so that the problem is reduced to counting the configurations of this chain. The result is that a phase change can indeed take place. It is not yet certain whether the conductivity drops to zero quite abruptly.

The title of the last section, "Non-ohmic Behaviour of Semiconducting Films and the Phenomenon of Switching", brings to mind the work of S. R. Ovshinsky, and he himself is in fact co-author of five articles. In one of them, with $\mathrm{H}$. Fritzsche, he discusses the conducting state in covalent alloy semiconductors which is maintained only above a certain value of the current, and the various processes that can trigger this high field breakdown. Another contribution by H. K. Henisch, E. A. Fagen and Ovshinsky discusses switching in monostable structures in terms of a double injection space charge model.

It is a pity that in a short review it is impossible to mention several other important contributions. In brief, we have here a collection of absorbing descriptions of the early exploration of a vast field.

L. Pincherle

\section{TALK AT CORAL GABLES}

Coral Gables Conference on Fundamental Interactions at High Energy 2

Center for Theoretical Studies, University of Miami, January 21-23, 1970. Edited by A. Perlmutter, Geoffrey J. Iverson and Ruth M. Williams. Pp. $\mathrm{x}+369$. (Gordon and Breach: London and New York, 1970.) \$22.50.

For several years now the University of Miami has been host to a winter conference on elementary particle physics organized by Professor B. Kursunoglu. The earlier meetings were restricted to symmetry physics and they provided valuable opportunities for discussion and exposition during the heady development of that subject in the middle sixties. Now that things are quieter on the symmetry front the scope of the conference has been widened to include a broader theoretical spectrum. The volume under review covers the second of the new style Coral Gables meetings held in January 1970. 